Revista do CESP, Belo Horizonte, v.35, n.54, p. 117-132, 2015

\title{
A soldadeira na língua dos jograis e dos trovadores
}

\section{The soldadeira in jongleurs and troubadours voices}

\author{
Viviane Cunha \\ Universidade Federal de Minas Gerais \\ vivi.cunha@terra.com.br
}

Resumo: No século XIII, período de apogeu da poesia galego-portuguesa, algumas mulheres se destacaram pela sua produção artística. Trata-se das jogralesas, mais conhecidas como soldadeiras, que interpretavam a música e a dança e recebiam um "soldo" como pagamento de sua arte, daí o seu nome. Os poetas trovadorescos as cantaram e satirizaram, o que pode ser percebido no repertório das cantigas de escárnio e de mal dizer, do Cancioneiro galego-português. Neste trabalho será enfocada uma soldadeira que tornou-se um ícone: Maria Balteira, cujas "performances" foram abordadas por vários trovadores.

Palavras-chave: poesia trovadoresca; cantigas de escárnio e mal dizer; soldadeiras.

Abstract: In XIIIth Century, gold period of Galician Portuguese poetry, some women can be distinguished by their art. They are the jongleuses, that were musicians and dancers, and gained money with their art, so they were called "soldadeiras". The Troubadours sung and satirized them, and this can be observed through the ensemble of the cantigas de escarnio and de mal dizer from Galician-Portuguese Cancioneiro. This paper will study a soldadeira that became a myth: Maria Balteira, whose performances can be found in the voices of many Troubadours.

Keywords: troubadours poetry; cantigas de escárnio and de mal dizer; jongleuses. 
118 Revista do CESP, Belo Horizonte, v.35, n.54, p. 117-132, 2015

Recebido em 8 de novembro de 2015

Aprovado em 22 de novembro de 2015

Desde a época em que o Cristianismo atingiu o seu apogeu, na Alta Idade Média, nas festas religiosas do noroeste da Península Ibérica, precisamente nas regiões onde se situam hoje Portugal e Galícia, as jogralesas costumavam cantar e dançar nos adros das igrejas ou das capelas dos povoados, e até mesmo nos espaços externos dos grandes santuários, como o de Santiago de Compostela. Desse período não se tem registros, mas pode-se inferir através das fontes indiretas, como a condenação da Igreja (através dos textos dos sermões), que as mulheres cantavam e dançavam nas festas religiosas. Essa presença das mulheres devia incomodar muito o clero, se considerarmos o que escreveu Cesário (470-542), o arcebispo de Arles: "obscoena et turpia cantica cum choris femineis". 1

A partir do movimento trovadoresco, em fins do século XII, surgiram os primeiros documentos sobre a arte das jogralesas, então transformadas em soldadeiras, as quais estão relacionadas com as cantigas galego-portuguesas. O nome soldadeira originou-se do fato de que recebiam um soldo, isto é, eram remuneradas para cantar e dançar. O Cancioneiro da Ajuda, o mais antigo dos três Cancioneiros galegoportugueses, datado de fins do século XIII ou início do século XIV, apresenta, nas suas iluminuras, as três figuras inseparáveis: o trovador, o jogral e a soldadeira. Esses personagens, como afirma Graça Videira Lopes, representavam um alvo fácil da perseguição satírica por parte dos trovadores. ${ }^{2}$

As jogralesas ou soldadeiras do noroeste da Península Ibérica, enquanto cantoras, dançarinas ou musicistas, constituíam uma categoria à parte, e procediam de diversas etnias e religiões - cristãs, muçulmanas ou judias - da mesma forma que os jograis. Eram artistas que cantavam, dançavam e tocavam seus instrumentos; malgrado isso, as cantigas satíricas galego-portuguesas sempre as retrataram como licenciosas. Contrariamente, as iluminuras do Cancioneiro da Ajuda apresentam delas uma imagem precisa, cantando ou dançando ao lado de um jogral. Pode-se compreender a importância das soldadeiras na lírica galego-portuguesa

\footnotetext{
${ }^{1}$ Apud NELLI. L'érotique des troubadours, p. 29.

${ }^{2}$ LOPES. Os ciclos satíricos nos Cancioneiros Peninsulares.
} 
através da sequência de iluminuras do Cancioneiro da Ajuda, que, como bem observou Menéndez Pidal, das 16 iluminuras que compõem o códice, 12 delas trazem uma cantora ao lado de um músico, sendo que os jograis aparecem apenas em 4 iluminuras. ${ }^{3}$ Mas, as soldadeiras não apresentavam apenas peças do Cancioneiro profano, também as Cantigas de Santa Maria eram executadas com a participação delas.

É provável que as soldadeiras, assim como os jograis, ganhassem a vida com certa dificuldade, pois as cantigas e também outros textos medievais mostram de ambos essa situação sócio econômica, de tal forma que havia uma hierarquia na classe das soldadeiras: as que possuíam alguma riqueza viajavam a cavalo; porém, havia também as que se deslocavam a pé de um lugar a outro, o que revelava a sua condição humilde. Possivelmente, as dificuldades financeiras não deixavam alternativas às soldadeiras, que deveriam "vender o seu corpo" algumas vezes, situação essa que virou mote dos trovadores, nas suas canções satíricas. Com efeito, no repertório satírico galego-português (cantigas de escárnio e de mal dizer) há um número considerável de poemas que apresentam uma imagem negativa da soldadeira.

Graça Videira Lopes, que estudou as cantigas de escárnio e de mal dizer galego-portuguesas, na sua tese de doutorado - publicada em 1994, pela Editorial Estampa, em Portugal - relata que o repertório satírico do Cancioneiro galego-português, composto de 465 cantigas, apresenta personagens dos mais variados tipos. As soldadeiras aparecem em 43 cantigas, as monjas aparecem em 10 cantigas, os trovadores e os jograis são apresentados em 86 cantigas, para citar apenas uma tipologia de personagens, que interessam neste estudo. Desse corpus de cantigas satíricas também fazem parte personagens os mais variados: clérigos, pessoas da alta nobreza, cavaleiros, escudeiros, etc., e ainda pessoas de diferentes etnias, como judeus e mouros. ${ }^{4}$

As cantigas satíricas apresentam um interesse principalmente histórico, uma vez que refletem uma imagem real da vida social, em particular da vida nas cortes, revelando detalhes da vida íntima da aristocracia, bem como dos trovadores, dos jograis, dos clérigos, das

\footnotetext{
${ }^{3}$ MENENDEZ PIDAL. Poesía juglaresca y origenes de las literaturas románicas, p. 33. ${ }^{4}$ LOPES. A sátira nos Cancioneiros medievais galego-portugueses.
} 
monjas, entre outros, e mostram a repercussão da reação pública em relação a certos fatos políticos. ${ }^{5}$

Os cancioneiros galego-portugueses apresentam dois tipos de poesia satírica: as cantigas de escárnio, que utilizam a ironia e o equívoco para apresentar uma crítica indireta, e as cantigas de mal dizer (preferimos adotar o termo mal dizer 'falar mal', mais correto do que maldizer, que pode ter outro significado no português atual), nas quais a sátira é direta, daí a sua virulência. Essa "lírica do realismo", como bem definiu Peter Dronke, ${ }^{6}$ se exprimia através de personagens reais, que se tornavam objeto da sátira, e se apresentava como o comentário de um fato social. Na opinião de Graça Videira Lopes:

(...) uma cantiga de escárnio e maldizer é, regra geral, uma composição circunstancial que brinca com ou ataca o comportamento de uma personagem do círculo onde se move o seu autor. Nesta medida, a variedade de temas e de motivos é o princípio básico da sua composição. Mas acontece que, nalguns casos, um trovador ou um jogral se fixa, a um dado momento, numa personagem, compondo a seu respeito uma série de cantigas satíricas. Potenciada deste modo, a sátira toma então a forma de uma espécie de perseguição poética e ganha, inevitavelmente, uma força suplementar. ${ }^{7}$

Efetivamente, é nas cantigas de caráter satírico que os trovadores execram as mulheres, sobretudo as religiosas - monjas ou abadessas - e principalmente as soldadeiras, esboçando-se aí um terreno fértil para a eclosão da misoginia medieval, atenuada em outros gêneros. Sirva de exemplo a cantiga de Afonso Eanes do Cotón (B 1579, V 1111), na qual o poeta - entenda-se o eu poético - pede a uma abadessa mais experiente que seja indulgente com ele, pois havia se casado muito jovem (ogano casei 'cedo me casei') e não sabia fornicar melhor do que um asno:

Abadessa, oí dizer
que érades mui sabedor
de todo ben; e, por amor

${ }^{5}$ LOPES. A sátira nos Cancioneiros medievais galego-portugueses.

${ }^{6}$ Apud LOPES. A sátira nos Cancioneiros medievais galego-portugueses.

${ }^{7}$ LOPES. Os ciclos satíricos nos Cancioneiros Peninsulares, p. 140. (grifo nosso) 
de Deus querede-vos doer

de min, que ogano casei,

que ben vos juro que non sei

mais que un asno de foder. ${ }^{8}$

O termo sabedor, no masculino, referindo-se à abadessa, explicase pelo fato de que a forma com o sufixo em -or servia aos dois gêneros: tanto ao masculino quanto ao feminino, da mesma maneira que o termo Senhor ( $c f$. mia Senhor) das cantigas de amor. A crítica do trovador Afonso Eanes do Cotón pode estar revestida, não apenas de certo caráter humorístico, mas também, moralista.

No corpus das cantigas galego-portuguesas de caráter satírico há uma soldadeira que se destacou, e transformou-se numa personagem quase mítica. Trata-se de Maria Peres, mais conhecida como Maria Balteira, protagonista de várias cantigas de escárnio e de mal dizer. Nascida em Arméa, próximo a Betanzos, na Galícia, ela herdou de seus pais - provenientes da pequena nobreza galega - algumas terras que lhe permitiram manter-se independente até o fim de sua vida. Apesar de sua origem social fidalga, ela é representada nas cantigas, como uma espécie de cortesã, com livre acesso nas cortes, a qual participa de expedições de cruzadas, e também, recebe pagamento pela sua arte de cantar e dançar.

Como soldadeira Maria Balteira frequentou as cortes do rei Fernando III e a de seu filho, Afonso X, o que permite situar o seu apogeu por volta de 1260 . Sua biografia pode ser traçada através das cantigas de caráter satírico, além de alguns documentos notariais do foro da Galícia. Os mais célebres poetas da corte de Afonso X, como Pero da Ponte, Pero de Ambroa, Pero Amigo de Sevilla, e o próprio rei castelhano compuseram cantigas sobre Maria Balteira, atribuindo-lhe alguns vícios, tais como o de jogadora de dados, de transmissora de doenças, de explorar as pessoas, e ainda de dormir com os clérigos, com os estudantes e com os jograis. A. Martinez Salazar, que escreveu a sua biografia, afirmou que ela era cantora e dançarina, e que fazia muitos trovadores "perderem a cabeça". ${ }^{9}$ Malgrado a sua arte como cantora e dançarina, as cantigas de

\footnotetext{
${ }^{8}$ Essa cantiga e todas as outras citadas neste artigo, foram retiradas de BREA. Lírica profana galego-portuguesa - Corpus completo das cantigas medievais, con estudio biográfico, análise retórica e bibliografia específica.

${ }^{9}$ Apud LAPA. Lições de literatura portuguesa.
} 
escárnio e de mal dizer relatam apenas a "outra arte" de Maria Balteira, como bem observou Ana Paula Ferreira. ${ }^{10}$

No corpus de sua pesquisa acima citada, Graça Videira Lopes ${ }^{11}$ arrolou 43 cantigas satíricas, que têm como personagens as soldadeiras. Segundo os textos, as soldadeiras parecem ter formado uma corporação organizada, juntamente com os jograis, mas disso há somente o testemunho das cantigas. A cantiga de Afonso X (B 481, V 64), que será analisada abaixo, refere-se além de Maria Balteira a outras três soldadeiras: Maior Moniz, Mari d'Aires e Alvela. Além dessas, Graça Videira Lopes cita na sua obra acima referida outras soldadeiras tais como: Maria Leve, Marinha Mijouchi, Marinha Lopes, Marinha Sabugal, Marinha Crespa, Marinha Foça, Domingas Eanes, Maria Mateu, Orraca Lopes, Maior Garcia, Elvira Lopes, Ouroana, Maria do Grave, Maria Negra, sem contar aquelas soldadeiras anônimas. ${ }^{12}$ Tudo leva a crer que Balteira era a preferida dos trovadores e dos jograis, tendo em vista que, pelo menos 15 cantigas relatam episódios nos quais ela é a protagonista.

Observe-se a cantiga de mal dizer do rei trovador Afonso X, na qual o recurso do equívoco apresenta certa ambiguidade. Joan Rodríguiz fora calcular junto à Balteira a quantidade de madeira - proveniente das florestas reais - que precisava para levar a cabo a sua construção:

Joan Rodríguiz foi osmar á Balteira sa midida, per que colha sa madeira; e diss'e[le]: - Se ben queredes fazer, de tal midid'a devedes a colher, [assí] e non meor, per nulha maneira.

E disse: - Esta é a madeira certeira, e, de mais, nõna dei eu a vós sinlheira; e, pois que s'en compasso á de meter, atan longa deve toda [de] seer, [que vaa] per antr'as pernas da'scaleira.

\footnotetext{
${ }^{10}$ FERREIRA. A "Outra Arte" das Soldadeiras.

${ }^{11}$ LOPES. A sátira nos Cancioneiros medievais galego-portugueses.

${ }^{12}$ LOPES. A sátira nos Cancioneiros medievais galego-portugueses.
} 

A Maior Moniz dei já outra tamanha, e foi-a ela colher logo sen sanha; e Mari'Aires feze-o logo outro tal, a Alvela, que andou en Portugal; e ja i a colheron [e]na montanha.
E diss': - Esta é a midida d'Espanha, ca non de Lombardia nen d'Alamanha;
e, por que é grossa, non vos seja mal, ca delgada pera gata ren non val; e desto mui mais sei eu ca Abondanha.

Essa cantiga, de caráter obsceno, apresenta o que a Arte de trovar - o tratado anônimo de poética galego-portuguesa, datado do século XIII - chama de hequivocatio (sic). Na realidade, Joan Rodríguiz, que era conhecido de Maria Balteira, de Maior Moniz, de Mari'Aires e de Alvela vangloria-se de possuir um membro viril, e para nomeá-lo, o poeta utiliza metáforas como: "madeira certeira", "midida", "tamanha" para referir-se ao órgão genital masculino do protagonista. Esse sentido ambíguo a Arte de Trovar esclarece muito bem, quando fala do equívoco nas cantigas satíricas:

Cantigas d'escarneo som aquelas que os trobadores fazen querendo dizer mal d'alguen en elas, e dizen-lho per palavras cubertas que hajan dous entendimentos, pera lhelo non entenderen... ligeiramente: e estas palavras chamam os clerigos "hequivocatio". E estas cantigas se podem fazer outrossi de mestria ou de refram, ${ }^{13}$

Na cantiga que será analisada em seguida, é interessante observar a figura multifacetada de Maria Balteira, a qual aparece como tendo participado de uma cruzada, numa cantiga de Pero da Ponte (B 1642, V 1176), e segundo o trovador isto the teria valido o perdão por sua vida de pecadora. Entretanto, quando ela retorna das terras distantes, o perdão já não tem mais valor ("e do perdon já non lhi ficou nada"), uma vez que continuava levando a mesma vida licenciosa. Após o seu retorno ela não pôde conservar o perdão conseguido como indulgência por ter participado da Cruzada, porque não possuía uma "maleta fechada" ("E o perdon é cousa mui preçada / e que se devia muit'a guardar; / mais ela

${ }^{13}$ TAVANI. Arte de trovar do Cancioneiro da Biblioteca Nacional de Lisboa, p. 42. 
nom á maeta ferrada"). Efetivamente, ela era a alegria dos jovens rapazes que estavam no mesmo albergue: "Tal maeta como será guardada pois rapazes albergam no logar, / que non aja seer mui trastornada / $\mathrm{Ca}$, o logar u eles an poder,/ non á pardon que s'i possa asconder, / assi saben trastornar a pousada”. Eis aqui a cantiga completa de Pero da Ponte, considerado um dos trovadores mais próximos de Maria Balteira:

$$
\begin{aligned}
& \text { Maria Pérez, a nossa cruzada, } \\
& \text { quando veo da terra d'Ultramar, } \\
& \text { assi veo de pardom carregada } \\
& \text { que se non podía com el en erger; } \\
& \text { mais furtan-lho, cada u vai maer, } \\
& \text { e do perdon já non lhi ficou nada. } \\
& \text { E o perdon é cousa mui preçada } \\
& \text { e que se devia muit'a guardar; } \\
& \text { mais ela non á maeta ferrada } \\
& \text { en que o guarde, nena pod'aver, } \\
& \text { ca, pois o cadead'en foi perder, } \\
& \text { sempr'a maeta andou descadeada. } \\
& \text { Tal maeta como será guardada, } \\
& \text { pois rapazes albergan no logar, } \\
& \text { que non aja seer mui trastornada? } \\
& \text { Ca, o logar u eles an poder, } \\
& \text { non á pardon que s'i possa asconder, } \\
& \text { assi saben trastornar a pousada. } \\
& \text { E outra cousa vos quero dizer: } \\
& \text { atal pardon ben se dev'a perder, } \\
& \text { ca muito foi cousa mal gaa[nha]da. }
\end{aligned}
$$

É, sem dúvida, a ambiguidade que provoca o riso, pois "guardar o perdão", um substantivo abstrato, significa antes, abster-se das relações sexuais, o que ela não pôde cumprir, porque sua maleta não tinha fecho ("maeta ferrada"), metáfora para exprimir o órgão sexual feminino. De acordo com as fontes históricas, Maria Balteira teria acompanhado Afonso X, na Cruzada contra o rei da Tunísia, pois havia notícia de que as soldadeiras eram também utilizadas frequentemente para fins políticos. Menéndez Pidal, fundamentando-se na tensão entre Pero Amigo de Sevilha e Vasco Peres, acredita que Afonso $\mathrm{X}$ teria tirado 
proveito da beleza de Maria Balteira, para manobras políticas junto aos muçulmanos. ${ }^{14} \mathrm{O}$ fato de uma mulher participar das Cruzadas não é de se surpreender, tendo em vista que Aliénor de Aquitânia - rainha da França e da Inglaterra - o fez, no século XII, apenas lembrando um dos nomes mais conhecidos dessa época. É sabido que as Cruzadas não consistiam somente em batalhas, ou eram exclusivas dos homens. Mulheres burguesas e grandes damas, esposas de comerciantes e artesãos, monjas e abadessas, e também, as mulheres submetidas a um tipo de escravidão e de exílio - como as turcas, as armênias, e as bizantinas participavam igualmente das Cruzadas, como ressaltou Régine Pernoud. ${ }^{15}$ Na realidade, participar de uma Cruzada à Terra Santa, para combater os inimigos da Cristandade - os mouros que haviam tomado Jerusalém tinha como objetivo alcançar o perdão por um grave pecado cometido, como um assassinato, um suicídio de um parente (neste caso seria uma penitência para salvação de sua alma), adultério e prostituição por parte da mulher, etc.

Outra cantiga que faz alusão ao contexto político da Península Ibérica, a saber, às lutas da Reconquista, é a de Pero d'Ambroa (B 1597, V 1129), na qual o poeta, ou antes, o "eu poético" se declara louco de amor por Maria Balteira ("que ando por ela sandeu"). Ela entretanto, queria vingar-se do mundo hostil que a desonrou, mas ele (o poeta, ou antes, o eu poético) não fazia parte desse mundo, já que se encontrava prisioneiro dos seus encantos: “ca en ssa prison and'eu / e d'ela non m'ei d'enparar"; a vingança deveria recair então sobre aqueles que a desonraram, a saber, os homens do reino de León e Castela e os do reino de Aragão. Efetivamente, à medida que os povos peninsulares foram reconquistando as suas terras que estavam sob o domínio árabe, foram se formando também os primeiros reinos, e no século XIII, os principais - Castela (unida com León), Aragão e Portugal - já haviam se fixado. De acordo com Menéndez Pidal, a alusão aos aragoneses e aos mouros, na terceira estrofe, com os quais Balteira teria tido contato, deve ser uma referência à fronteira de Murcia, quando os árabes dessa região caíram sob o domínio de Castela e sob o domínio do rei Jaime I, de Aragão,

\footnotetext{
${ }^{14}$ Apud LAPA. Lições de literatura portuguesa.

${ }^{15}$ PERNOUD. Les femmes aux temps des croisades.
} 
no momento em que Afonso X lutava contra os mouros em Granada. ${ }^{16}$ Observe-se a cantiga:
$\mathrm{O}$ que Balteira ora quer vingar
das desonrras que no mundo prendeu, se ben fezer, non dev'a começar en mi, que ando por ela sandeu, mais começ'ant'en reino de Leon, hu pres desonrras de quantos hi son, que lh'as desonrras non queren peitar.
$\mathrm{Ca}$ en Castela foi a desonrrar muito mal home, que non entendeu o que fazia, nen soube catar quan muit'a dona per esto perdeu; e, quen a vinga, fezer con razon d'estes la vingue, ca en ssa prison and'eu e d'ela non m'ei d'enparar.
E os mouros pensse de os matar, ca de todos gram desonrra colheu no corpo, ca non en outro logar; e outro tal desonrra recebeu dos mais qu'á no reïno d'Aragon: e d'este la vingu'él, ca de min non, pois á sabor de lhi vingança dar.

Sempre é bom lembrar que durante o período cruciante da Reconquista, a qual durou oito séculos, todos os reinos da Península Ibérica - excetuando Portugal, que já se tornara independente, em 1143 - foram anexados a Castela, o que foi determinante para a unificação da Espanha. A cantiga em questão confirma a presença de Maria Balteira nesse contexto sociopolítico, retratando a maneira como ela foi "usada" para fins não muito nobres, e toda a sua revolta: "pois á sabor de lhi vingança dar".

Na Cantiga de Fernan Velho (B 1504), Balteira aparece como uma arrependida que pede perdão a Nosso Senhor e deseja a presença de um clérigo junto a ela, para que possa confessar-se, e assim se proteger do

\footnotetext{
${ }^{16}$ O filólogo espanhol se baseia nos seus Documentos linguísticos, que publicou em 1919, p. 481.
} 
diabo que sempre esteve em sua companhia. Porém, ela seduz o clérigo e ambos se enamoram um do outro, por obra do diabo. Nos dois versos finais o diabo é vencido, quando ela confessa seus pecados. Observemos a cantiga do trovador Fernan Velho:

Maria Pérez se maenfestou

n'outro dia, ca por [mui] pecador

se sentiu, e log'a nostro Senhor

pormeteu, polo mal en que andou,

que tevess'un clerig'a seu poder

polus pecadus que lhi faz fazer

o demo, con que x'ela sempr'andou.

Maenfestou-sse, ca diz que s'achou

pecador muyt', e por én rogador

foy log'a Deus, ca teve por melhor

de guardar a el ca o que aguardou;

$\mathrm{e}$, mentre vyva, diz que quer teer

hun clerigo con que se defender

possa do demo, que sempre guardou.

E poys que ben seus pecados catou, de sa mort[e] ouv'ela gran pavor e d'esmolnar ouv'ela gran sabor; e logu'enton hun clerigo filhou e deu-lh'a cama en que sol jazer, e diz que o terrá, mentre viver. e est'afam todo por Deus filhou!

E poys que s'este preyto começou antr'eles ambus, ouve grand'amor antr'ela sempr' [e] o demo mayor, ata que se Balteira confessou. Mays, poys que vyo o clerigo caer antr'eles ambus, ouvi-a perder o demo, des que s'ela confessou.

Trata-se de uma cantiga de mal dizer, cuja crítica dirige-se aos clérigos. É bom lembrar que neste gênero de cantiga a crítica é direta e o poeta (ou o eu poético) costuma dirigir-se tanto a uma pessoa em particular como a uma classe social, no presente caso é endereçada ao clero. 
Na Idade Média, os jogos de azar constituíam um pano de fundo da paisagem lúdica, e entre eles, os dados eram os mais citados nas fontes literárias e / ou históricas. Desde o século XIV, nas representações iconográficas sobre a Crucificação de Cristo aparecem os soldados romanos disputando, nos dados, as Suas roupas. Curiosamente, o texto bíblico, ao fazer alusão a esse episódio, fala simplesmente de se "tirar a sorte".

Nesse sentido, a cantiga de Pero Garcia de Burgalés - cujo sobrenome sugere que seja de Burgos, como o supõe Carolina Michaëlis de Vasconcelos, o qual fazia parte da corte de Afonso X - não causa surpresa. O trovador (entenda-se eu poético) deplora o fato de Maria Balteira jogar dados (“... por que jogades os dados ...?"), atividade proibida às mulheres, e sobretudo a uma mulher de "boas maneiras" ("pero muytas boas maneyras ajades"). Acrescenta ainda um alerta de que os dados serão a sua perdição, bem como a de um homem de valor que poderia eventualmente ser seu pretendente ( $3^{\text {a }}$ estrofe). Observe-se a cantiga de Pero Garcia de Burgalés (B 1374, V 982):

Maria [B]alteyra, por que [j] ogades os dad[o]s, poys a eles descreedes?

Hunhas novas vus direy, que sabhades:

con quantos vus conhocem vus perdedes, ca vus direy que lhis ouço dizer: que vos non devedes a descreer, poys dona sodes e jogar queredes.

$\mathrm{E}$, se vus daquesto non castigades, nulh'ome non sey con que ben estedes, pero muytas boas maneyras ajades, poys, ja daquesto tam gram prazer avedes de descreerdes; e direy vus al: se volo oyr, terrá volo a mal bon ome, e nunca con el jogaredes.

E nunca vos, dona, per mi creades, per este descreer que vós fazedes, se en gram vergonha poys non entrades alg, a vez con tal hom'e mar[r]edes: ca sonharedes nos dados enton, e se descreerdes, se Deus mi perdon, per sonho, mui gran vergonça averedes! 
A decadência de Maria Balteira também foi objeto das sátiras dos trovadores. Carolina Michaëlis de Vasconcelos, citando seu biógrafo A. Martinez Salazar, supõe que o momento glorioso de sua vida deva ter sido antes de 1257. Joan Baveca, um jogral galego, a pinta como uma velha, na cantiga (B 1460, V 1070), que citamos a seguir:

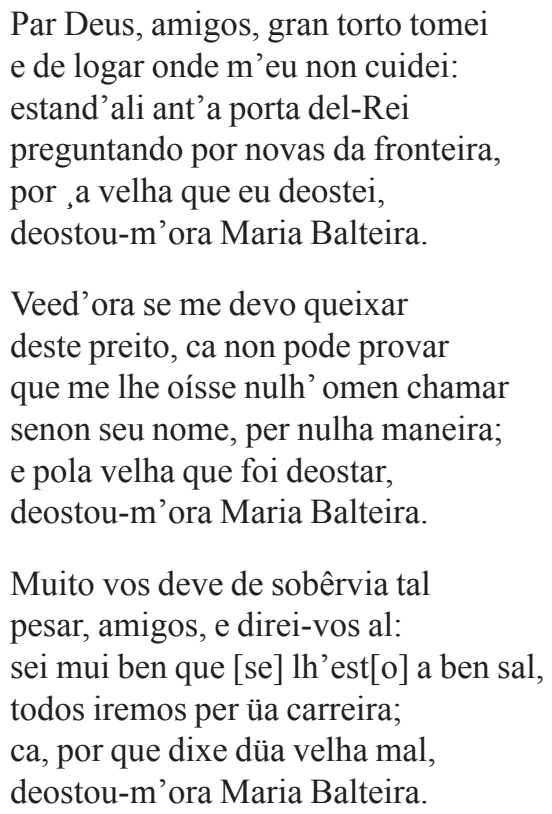

O poeta a encontra "à porta do rei" ("ant'a porta del-Rei"), no momento em que ali estava para pedir notícias da fronteira ("preguntando por novas da fronteira"). No refrão, o poeta exprime seu desagrado ao contemplar a imagem de Balteira, pois ela é já uma velha, que lhe causa vergonha ("por üa velha que eu deostei, deostou-m'ora Maria Balteira"). Envelhecendo, a antiga "peregrina" da Terra Santa tornava-se mais piedosa e se encontrava junto a um confessor, repetindo: "Sõo vella, ay capelam!" (Refrão de outra cantiga sobre Balteira não estudada aqui).

$\mathrm{Na}$ realidade, há que se refletir sobre a seguinte questão: se os trovadores eram amigos das soldadeiras, se possivelmente dividiam entre si a atenção da corte (conforme o caso de Balteira), qual seria a razão das críticas a elas dirigidas ? Pode-se pensar, talvez, que o teor das cantigas satíricas dirigidas às soldadeiras fosse antes um jogo de escritura, uma paródia do cotidiano com o intuito de divertir o público, mais do que 
repreensão ou moralismo. Ao carnavalizar o universo das soldadeiras, para usar um termo de Bakhtin, os poetas medievais encontraram, talvez, uma forma de perpetuar uma classe - a dos jograis e jogralesas - e chamar a atenção para suas condições de vida, que deveriam contrastar enormemente com as da corte a qual divertiam. Dessa forma, além de diversão as cantigas teriam uma função de denúncia social.

Quinze poemas ou mais foram dedicados a essa soldadeira da corte do rei Afonso X, e 11 trovadores (incluindo-se entre eles o próprio rei) cantaram as suas relações com os clérigos, com os jograis, com os homens mais jovens. Eles cantaram também os seus vícios e os seus pecados: jogadora de dados, mentirosa, e muitos outros adjetivos. Segundo Graça Videira Lopes, ${ }^{17}$ Maria Balteira foi a única soldadeira da qual foi possível traçar uma biografia. Pode-se vê-la numa cantiga de Pero d'Ambroa - com quem ela teve uma ligação mais forte - chorar indiretamente (através das palavras do poeta) as desonras que conheceu neste mundo: "das desonrras que no mundo prendeu”, (B 1597, V 1129). Balteira possuía terras na Galicia, e a partir de um documento (datado de 1257) de venda ao Mosteiro de Sobrado, de uma propriedade sua, pôde-se concluir que ela passara seus últimos momentos de maneira confortável. Segundo o documento em questão, o mosteiro era obrigado a pagar-lhe um aluguel durante sua vida e a ocupar-se de seus funerais, programados segundo os termos, para serem realizados com certa pompa.

$\mathrm{O}$ apogeu das soldadeiras coincidiu com o período mais importante da escola dos trovadores galego-portugueses: o século XIII. Entretanto, parece que elas continuaram ativas até o século XIV, a julgar pela imprecação que lhes dirigiu o Concílio de Toledo (1324):

Nossa jurisdição está penetrada de uma detestável imoralidade, uma vez que as donas que o povo chama de soldadeiras entram publicamente nas casas dos prelados e dos ricos homens, convidadas para a mesa; impregnadas de conversações depravadas e de propósitos desonestos, elas corrompem os bons costumes, e o que é pior, elas fazem espetáculos (dançarinas), é por isso que ordenamos a todos, especialmente aos prelados, que lhes façam ameaças com os castigos do Céu, para que eles não permitam a tais

${ }^{17}$ LOPES. A sátira nos Cancioneiros medievais galego-portugueses. 
donas entrar nas suas proprias casas, nem façam delas suas mulheres. ${ }^{18}$

É possível que aquele século fosse também o do fim das soldadeiras, pois, a partir de 1330, não se falava mais de soldadeiras, mas sim de cantoras, que segundo o poeta Arcipreste de Hita, na sua obra Libro de Buen Amor, cantavam com um pandeiro. No que concerne a Maria Péres Balteira, ela se tornou um símbolo da mulher que superou o seu tempo, uma vez que é cantada até hoje pelos poetas galegos.

\section{Referências}

BREA, Mercedes (Coord.) et al. Lírica profana galego-portuguesa. Corpus completo das cantigas medievais, con estudio biográfico, análise retórica e bibliografia específica. 1. ed. Santiago de Compostela: Xunta de Galicia, 1996. 2 v.

Cancioneiro da Ajuda. Edição crítica de Carolina Michaëlis de Vasconcelos. Reimpressão da edição de Halle (1904), Lisboa: Imprensa Nacional - Casa da Moeda, 1990. 2 v.

Cancioneiro da Ajuda. Edição fac-similada do Códice existente na Biblioteca da Ajuda. Apresentação, Estudos e Indices. Lisboa, Edições Távola Redonda. Instituto Português do Patrimônio Arquitectónico e Arqueológico. Biblioteca da Ajuda, 1994.

Cancioneiro da Biblioteca Nacional (Colocci-Brancuti) Cod. 10991. Lisboa, Biblioteca Nacional - Casa da Moeda, 1982. Apresentação de L. F. Lindley-Cintra. Edição fac-similada.

Cancioneiro Português da Biblioteca Vaticana. Cod. 4803. Lisboa, Centro de Estudos Filológicos - Instituto de Alta Cultura, 1973. Apresentação de L. F. Lindley-Cintra. Edição fac-similada.

FERREIRA, Ana Paula. A “Outra Arte" das Soldadeiras. Luso-Brazilian Review, v. 30, n. 1, 1993.

LAPA, Manoel Rodrigues. Lições de literatura portuguesa. Época Medieval. 4. ed. revista. Coimbra: Coimbra Editora, 1955.

${ }^{18}$ Colecc. de cánones y concilios, por J. Tejada y Ramiro, III, p. 522, apud MENÉNDEZ PIDAL. Poesía juglaresca..., p. 59 (nossa tradução do espanhol). 
132 Revista do CESP, Belo Horizonte, v.35, n.54, p. 117-132, 2015

LAPA, Manoel Rodrigues. Cantigas de escarnho e de mal dizer dos cancioneiros medievais galego-portugueses. Edição crítica. Santiago de Compostela: Editorial Galaxia, 1965.

LOPES, Graça Videira. A sátira nos Cancioneiros medievais galegoportugueses. Lisboa: Editorial Estampa, 1994.

LOPES, Graça Videira. Os ciclos satíricos nos Cancioneiros Peninsulares. In: Ondas do Mar de Vigo. Actas do Simposio Internacional sobre a Lirica Medieval Galego-Portuguesa. Coord. Por Derek W. Flitter e Patricia Odber de Baubeta. Birmingham: 1998. p. 139-146.

MENENDEZ PIDAL, Juan Ramón. Poesía juglaresca y orígenes de las literaturas románicas. 6. ed. corregida y aumentada. Madrid: Instituto de Estudios Políticos, 1957.

NELLI, René. L'érotique des troubadours. Toulouse: Edouard Privat, 1963.

PERNOUD, Régine. Les femmes aux temps des croisades. Paris: Livre de Poche, 1999.

TAVANI, Giuseppe. Arte de Trovar do Cancioneiro da Biblioteca Nacional de Lisboa. Introdução, edição crítica e fac-simile. Lisboa: Ed. Colibri, 2002. 